\title{
Understanding mammary gland functioning in livestock species using in-vitro mammary epithelial cells model -An overview
}

Umesh Kumar Shandilya ${ }^{1}$, Monika Sodhi ${ }^{2}$, Ankita Sharma $^{3}$, Neha kapila ${ }^{4}$, M Mukesh $^{\dagger}$ Animal Biotechnology Division, National Bureau of Animal Genetic Resources, Karnal, Haryana-132001, India

\author{
${ }^{1}$ ukshandilya@gmail.com \\ 2 monikasodhi@yahoo.com \\ 3 ankitasharma21@gmail.com \\ 4 nehakapila17@gmail.com
}

ABSTRACT

† Corresponding Author: mmukesh_26@hotmail.com

\begin{abstract}
Understanding the mechanisms of the development of the mammary gland can increase the efficiency of milk production, as well as improve animal health. Mammary epithelial cells (MEC) are the functional unit of the mammary gland. Although, there is a well-established MEC cell line, known as MAC-T, the use of a primary cell line is preferred because it more closely mimics an in vivo model. This review focuses on utilization of MECs as a potential in vitro model to better understand mammary gland functions in livestock species. Recently, considerable advances in three dimensional modeling of the mammary gland have been made with the used of extracellular matrix for the study of branching morphogenesis which may enable rapid advances in our understanding of mammary gland biology. Progress in the exploitation of MECs as in vitro model is more productive than ever, however further research is vital.
\end{abstract}

\section{Indexing terms/Keywords}

Mammary gland; mammary epithelial cell; cell culture.

\section{Academic Discipline And Sub-Disciplines}

Biotechnology

\section{SUBJECT CLASSIFICATION}

Cell culture

\section{TYPE (METHOD/APPROACH)}

Review article

\section{Council for Innovative Research}

\author{
Peer Review Research Publishing System
}

\section{Journal: Journal of Advances in Biotechnology}

\author{
Vol. 3, No.1
}




\section{INTRODUCTION}

The mammary gland is a special organ that undergoes natural cycles of proliferation, differentiation and apoptosis, as well as remodeling, throughout life under the cyclical influences of multiple steroid and polypeptide hormones [1]. These developmental events are regulated in response to a precise interplay between epithelial cells and their surrounding microenvironments as well as outer environmental conditions [2,3]. In addition to the soluble factors recognized for their role in growth control, microenvironments are also comprised of multiple stromal cells as well as insoluble glycoproteins of extracellular matrix (ECM). Growing evidence has indicated an important role played by the stromal cells in regulating normal mammary tissue morphogenesis and their aberrant behavior during the progression of breast cancer [4,5]. However, an explanation for these processes at different levels of cell and tissue complexity remains sparse due to a lack of appropriate model systems for study.

Because of the commercial value of milk there is a great interest in understanding mechanisms involved in milk protein expression and udder resistance to pathogens which cause infectious agalactia or secretion of abnormal milk. Demanding transcriptomic studies investigating mechanisms influencing mammary gland metabolism usually involve in vivo experiments. Additionally, treatments in vivo can have systemic effects which make controlling the environment of epithelial cells in a predictable way very difficult [6] for this reasons adequate in vitro model mimicking the function of the mammary gland would be of great importance for the study of physiological, biochemical and immunologic functions of the mammary gland. Furthermore, there are almost no techniques that would allow the maintenance of organs ex vivo long enough to permit necessary molecular biological investigations. As such, an enormous potential exists in the use of threedimensional (3-D) cell culture models as surrogates for tissues. In the recent years, mammary cell culture models were mainly used to study cell differentiation during lactation, innate immune response to infections and response to hormonal induction of lactogenesis in mammary epithelial cells (MECs).

Several ruminant immortalized cell lines such as MAC-T [7] and BME-UV [8] have been established by stable integration of the simian virus large T-antigen (SV40LtA). However, because of their low responsiveness to lactogenic hormones, transformed mammary cell lines were mainly used to study insulin growth factor 1 (IGF-1) metabolism [9]. It is still not clear how modifications in immortalized cell lines alter physiological pathways of transformed cells, therefore the use of primary cell lines is much more representative of the in vivo system maintaining organ-specific functions and signal transduction pathways [10].

\section{CHARACTERIZATION OF MAMMARY EPITHELIAL CELLS (MECS)}

Demanding transcriptomic studies in combination with challenging experiments in livestock animal species could be replaced by good in vitro models mimicking the function of ruminant mammary gland. When using tissue explants, however, it is inherently difficult to distinguish between primary mitogens and secondary regulators of mammary gland function/development. To circumvent most of these difficulties, emphasis has been placed on cell culture methodologies to study growth regulation, hormonal responsiveness, or biochemical properties of mammary epithelial cells (MEC). Previous works have led to the development of stable epithelial cell lines of bovine mammary gland $[7,11,12]$. The concentration of fetal bovine serum (FBS) in media had a strong effect on the proliferation of bovine mammary epithelial cells. When compared with $0 \%$ FBS treatment, bovine mammary epithelial cells grown in 5 to $10 \%$ serum underwent a 3-to 4-fold increase in cell number during the $12 \mathrm{~d}$ of culture [13]. Cloned bovine mammary epithelial cells also depended on FBS for proliferation and a marginal advantage could be attributed to the higher FBS concentration (10\% FBS) [9]. Vimentin is the intermediate filament protein normally expressed by cells of mesenchymal origin. Vimentin is considered as a marker of myoepithelial cells [9]. However, cytokeratin 18 is one of the most common members of the intermediate filament gene family, and generally exists together with its filament partner keratin 8. It is expressed in single layer epithelial tissues of the body and is specific for epithelial cells [10]. Immunocytochemical staining of goat mammary tissue showed that vimentin was present in myoepithelial cells but not in epithelial cells. However, cytokeratin 18 was found in both epithelial and myoepithelial cells of the goat mammary gland [14]. Bovine myoepithelial cells were positive to anti-vimentin and negative to anti-cytokeratin-18 monoclonal antibody [15]. Primary bovine mammary epithelial cells with characteristic fibroblast morphology were positively-stained with anti-vimentin [15]. The different result is that vimentin was also seen in lactating bovine mammary gland epithelial cells grown without hormones; whereas, cultures grown in the presence of hormones expressed only cytokeratins, which are specific for epithelial cells [16]. Rose et al. [17] found monolayers of bovine mammary epithelial cells were stained positive for anti-pan-cytokeratin, anti-type VII cytokeratin than for vimentin. They suggested that the epithelial cells grown on plastic plates had some characteristics of myoepithelial cells for weak positive staining to vimentin.

To assess the differentiating capacity of buffalo MECs (BMECs) the cells were grown on attached collagen type I matrix. The morphological differentiation of BMECs to duct-like and acini-like structures on attached collagen gels provide evidence for their responses to microenvironment [11]. Different MEC lines from different species viz, bovine [6], caprine [9] and ovine [18], mouse [19], human [20] have been found to undergo collagen mediated morphological and functional differentiation resulting in duct and mammospheres. Integrins play a significant role in cell attachment, spreading and migration in vitro. Human normal MECs have been reported to form ridges and ball-like structure when collagen fibrils were added to mammary epithelial cells [21] which results due to integrin mediated morphogenesis.

Cytoskeleton expression is important in identifying epithelial cell lineage. Cytokeratins are intermediate filaments of epithelial cells and are important in defining the cell phenotype [22]. It has been reported that cytokeratin filaments appear as interconnected bundles in the cytoplasm. The cytokeratin network is denser around the nucleus, cytoplasmic vesicles and in the periphery of the cell where the filaments run parallel to the cell surface, which after several subcultures may 
reduce to the area surrounding the nucleus [23]. Cytokeratin 18 is normally associated with simple epithelium and all luminal epithelial cells of human mammary gland. Positive reaction of BMECs with anti-cytokeratin 18 antibody indicated their luminal epithelial lineage.

Casein secretion is considered as an important feature of mammary epithelial cells. Differentiation of MECs is characterized by expression of milk protein such as b-casein, whey acidic protein and milk fat [24]. Milk fat droplets are secreted from MECs by a budding process in which droplets of triglyceride formed in the cytoplasm are gradually enveloped by a layer of apical plasma membrane called milk fat globule membrane (MFGM). Butyrophilin (BTN1A1) an acidic glycoprotein comprises over $40 \%$ by weight of total protein of bovine MFGM [25] and is specific to mammary tissue and only expressed at high levels on the apical surfaces of secretory MECs during lactation [26]. Expression of BTN1A1 and $\beta$-casein (CSN2) are considered to be the response of the mammary epithelial cells to hormonal induction [27].

\section{HEAT STRESS STUDIES}

Heat stress is a significant financial burden to animal agriculture in most areas of the world. During warm summer months milk production can decrease between 10 to $35 \%$ and this is a costly issue in dairy industry [28]. Environmental heat stress on livestock can affect reproductive efficiency, milk composition, milk yield, and animal health. It is not completely understood why stress has such adverse effects on dairy animals and has always been a major concern for livestock industry. So, mammary gland is used as a model to study the effect of heat stress for the identification of the underlying gene networks and molecular pathways associated with heat stress in our native livestock species. The effects of mild hyperthermia on bovine mammary epithelial cells and the results showed that the cell viability, ultrastructural features as well as mitochondrial function were significantly influenced by the mild heat treatment [29]. This depression in cell viability and occurrence of bovine mammary cell apoptosis and necrosis was induced through the mitochondrial-triggered cell death pathway, which further induces G2/M arrest by DNA damage. It has been long suggested that mitochondria may be directly involved in the heat-shock cellular response [30]. MECs are sensitive to environmental changes and reported to be used as in-vitro model for evaluating hyperthermia induced damage [29,31]. In addition, the MECs culture model has been used to study growth characteristics and cellular level changes during environmental heat stress [27, 29,32-34]. Further it is reported that the thermal stress induced the changes in gene expression along with the rapid regression of bovine mammary epithelial cells ductal structures [35]. The results to date indicate that a portion of the loss in milk yield during acute thermal stress is associated with direct effects of thermal stress on mammary epithelial cells. Overall, the transcriptome profile indicated down-regulation of genes involved in cell structure, metabolism, biosynthesis, and intracellular transport and of the up-regulated genes, the majority were involved in cellular repair, protein repair, and apoptosis after loss of thermotolerance. These data indicate that morphogenic activity in the mammary epithelium might depend upon the expression profile of a core set of genes, and that structural assembly might be controlled at the genomic level. So it was concluded that the acute heat stress of growing mammary epithelial cells directly reduces cellular growth and ductal branching and down regulated genes associated with protein synthesis and cellular metabolism. The mammary gland is a complex and highly specialized tissue with diverse physiological, biochemical and immunological functions.

\section{CELL-CELL INTERACTION STUDIES}

In 2D mammary epithelial model systems, glucocorticoids contribute to cell-cell interactions by inducing there organization of tight and adherens junctions leading to enhanced cell-cell adhesion and decreased paracellular permeability [36-37]. Essential cell-cell interactions occur via the epithelial junctional complex of tight junctions, adherens junctions, and desmosomes [38]. Debnath et al. [39] suggest that a primary event in acinus formation is establishment of epithelial cell polarity. The establishment of polarity in epithelial cells most probably goes hand-in-hand with the development of cell-cell contacts through apical junctions [38]. Firestone and coworkers [36-37, 40-41] suggest that in mammary tumor cell monolayers, glucocorticoids induce tight junction formation and cell polarity through a multi-step cascade involving early rapid stimulation of the transcriptional regulator, Id-1, and later induced recruitment of tight junction proteins, adherens junction proteins and Ras and PI3 kinase signaling proteins to the sites of cell-cell contact [40]. This parallels necessary down-regulation of fascin, an adherens junction-associating actin-bundling protein [37].This work suggests that glucocorticoids act to support acinus formation and may do this by regulating the expression of proteins required for cellcell (ZO-1 and occludin) and ECM-cell contacts ( $\beta 4$ integrin). Milk protein expression is triggered by prolactin stimulation acting through the JAK1/STAT5 signaling pathway [42]. However, it has been shown that treatment with prolactin in isolation is insufficient to induce STAT5 signaling and $\beta$-casein expression in primary mammary epithelial cell cultures [43] and cell lines [44]. The biochemical signaling from the extracellular matrix, cell-cell signaling mechanisms coordinate to maintain epithelial polarity and differentiation. Gap-junction connexin expression was found to be localized to regions of cell membrane when CID-9 cells were grown on EHS-matrix in contrast to a plastic substrate where it remained cytosolic. Furthermore $\beta$-casein expression was dependent on gap-junction mediated inter-cellular signaling and was absent in the presence of functional blocking antibodies of $\beta 1$ integrins, and inhibitors of cAMP [45]. Disrupting Rac1, a GTPase involved in cortical actin remodeling, resulted in the disorganization of laminin deposition by a kidney epithelial cell line (MDCK) and a resultant loss of polarity [46]. The surrounding stroma, which supports the glandular epithelium is more than just a passive supporting structure. It contains many cell types including fibroblasts, adipocytes and inflammatory cells that can influence the epithelium by releasing growth factors and cytokines or directly modulating the extracellular matrix in which the cells reside [47]. The gross influence of the stroma was highlighted in early heterotypic recombination experiments where microdissected mammary epithelia were recombined and cultured within salivary gland stroma [48] The resulting epithelial tissue morphology closely resembled dichotomous branching patterns typical of salivary gland. Similar work recombining highly branched mammary epithelia with the epithelium-divested mammary fat pads of sparsely branched glands resulted in a sparsely branched morphology [49]. Despite the utility of cell lines, there is a pressing need 
for better models of mammary gland development that recapitulate branching morphogenesis, lobuloalveolar development and stromal interactions. This is important for both studies of mammary gland biology and breast cancer.

\section{THREE-DIMENSIONAL CULTURE}

Growth of primary mammary cell cultures from lactating mammary gland on plastic usually results in loss of tissue specific functions. Cells in this state do not synthesize any of the milk components nor do they have the cellular response of in vivo cells [50]. In contrast to the limitations inherent to two-dimensional (2D) culture systems, many aspects of organization of mammary epithelial structures were recapitulated in vitro when primary mammary epithelial cells or established cell lines were exposed to a 3D physiological exogenous matrix, e.g. collagen, Matrigel [51-53]. Recently, the advent of three dimensional (3D) culture models has allowed investigators to make significant progress toward characterizing factors involved in the establishment and maintenance of epithelial architectures [51,54]. The growth of MECs on pre-formed extracellular matrices results in morphological differentiation as well as in synthesis of milk components [17]. Kabotyanski et al. [55] studied transcription of $\beta$-casein (CSN2) and suggested that the expression of CSN2 is induced synergistically by lactogenic hormones together with local growth factors, cell-cell and cell-substratum interactions. However, while the use of 3D culture systems has proven to be advantageous in the characterization of behavior of a single human mammary cell type (especially epithelial cells), these studies have largely ignored the fact that no epithelial cells exist as "isolated islands" in the mammary tissue in vivo [39]. Monolayer culture models are easy and convenient in vitro systems, however they do not recapitulate the glandular structure of epithelium in vivo, thus cannot provide the optimal system for studying the regulation of proliferation, polarization and differentiation of glandular epithelium. The development of three dimensional (3D) cell culture models has allowed investigators to make significant progress toward characterization of the factors involved in the establishment and maintenance of epithelial architecture. Three dimensional (3D) basement membrane cultures provide a unique opportunity to model the architecture of epithelium in vitro [38].Unlike monolayer cultures, mammary epithelial cells (MECs) grown in 3D recapitulate numerous features of glandular epithelium in vivo, including the formation of growth-arrested polarized acini with a hollow lumen and basal deposition of basement membrane components, such as collagen IV and laminin V [56-59]. The work by Delabarre et al. [60] showed that the primary bovine MECs cultured on EHS-matrix-coated inserts attached easily and rapidly reorganized the substratum into alveolar structures. The same cells seeded on type I collagen-coated inserts reorganized a typical epithelial cell pavement when cell seeding density was sufficient. Moreover they developed tight junctions, desmosomes and apical microvilli. Bovine BME-UV1 cells form 3D acinar structures mammo-spheres upon seeding on Matrigel. The same cell line plated on tissue culture dishes grows in monolayer forming a typical epithelial cobblestone structure. The bovine MECs undergo a series of proliferative and morphogenic events resulting in the formation of growth-arrested mammospheres, composed of a single layer of polarized epithelial cells, which remain in direct contact with basement membrane components, and surround a hollow lumen [61]. A similar rate of acinar structure development was observed in human and mouse mammary epithelial cell lines cultured on Matrigel: MCF-10A matured during 16-20 days, HC11 cells were grown for 10-12 days in 3D culture to form acini with polarized cells surrounding an empty lumen [62-63].

\section{METABOLOMIC STUDIES}

Mammary epithelial cells are being used for study of metabolomics of mammary gland. An understanding of the mechanism and regulation of metabolite uptake in the mammary gland is necessary to increase milk production in livestock. Recent studies [64- 67] have found that GLUT1 is most abundantly expressed in mammary glands and that the levels increase during pregnancy and peak during lactation, results that may be related to the abundant synthesis of proteins and lactose in breast tissue. GLUTs are expressed in every cell of the body and provide the metabolic energy and building blocks for the synthesis of biomolecules and control glucose utilization, glucose production and glucose sensing [68]. Glucose is of central metabolic importance in virtually all organisms, and is pivotal in lactating animals because glucose is the primary precursor of lactose synthesis, and lactose controls the milk volume by maintaining osmolarity of milk [69]. The increased glucose availability stimulated glucose uptake by the mammary epithelial cells. However, the high concentrations of glucose enhanced BMEC proliferation [70].The glucose availability did affect the glucose transport and utilization by the BMEC. The intermediary metabolites of glucose, such as glucose-6-phosphate and NADPH can actas survival factors [71-72], and cell growth is dependent on energy supply [73-74]. Aboagye and Bhujwalla [75] reported that choline phospholipid metabolite levels progressively increase in cultured HMECs as cells become more malignant. In the model system used here, phosphocholine levels and total choline containing phospholipid metabolite levels increased with progression from normal to immortalized to oncogene-transformed to tumor-derived cells. So it was propose that carcinogenesis in human breast epithelial cells results in progressive alteration of membrane choline phospholipid metabolism. TGF- $\beta$ reversibly induced an alteration in the differentiation of normal mammary epithelial NMuMG cells from epithelial to fibroblastic phenotype. The change in cell morphology correlated with (a) decreased expression of the epithelial markers E-cadherin, ZO-1, and desmoplakin I and II; (b) increased expression of mesenchymal markers, such as fibronectin; and(c)a fibroblast-like reorganization of actin fibers. This phenotypic differentiation displays the hallmarks of an epithelial to mesenchymal transdifferentiation event [76]. Basement membrane extracellular matrix (ECM), but not fibronectin or collagen, was shown to suppress apoptosis of mammary epithelial cells in tissue culture and in vivo. The results suggested that ECM regulates apoptosis in mammary epithelial cells through an integrin-dependent negative regulation of ICE expression [77].

\section{TRANSCRIPTIONAL STUDIES}

Mammary epithelial cells are also utilized as model to understand the transcriptional changes occur during lactation cycle viz lactation and involution. Environmental stress causes several anomalies to the MECs such as inhibition of protein 
synthesis, defects in protein structure and cytoskeleton deformation. These anomalies invoke large changes in gene transcription and protein synthesis which ultimately determine cell survival and acclimation or cell death. Collier et al., [32] studied the transcriptome profile in mammary epithelial cells indicating down regulation of genes involved in cell structure, metabolism, biosynthesis, and intracellular transport. HSPs regulate the cellular response to thermal stress and affect expression of a wide variety of genes and associated pathways. Transcriptome differences indicated the evidences for paracrine interactions between tissues in stimulation of IGF1 signaling pathway, stromal reaction, angiogenesis, neurogenesis, and immune response. Casey et al. [78] showed that GHR and PRLR transcripts possess higher expression in the epithelial compartment indicate the response of mammary gland towards systemic effects of respective hormones during this period of development. The epithelial cells were characterized with blocks that regulate protein synthesis, metabolism and secretion processes. Several transcription factors can regulate FA synthesis. One family of transcription factors designated sterol regulatory element binding proteins (SREBP), which belong to the basic helix-loophelix leucine zipper family, are known to regulate FA synthesis [79]. Different SREBP isoforms have different roles in regulating lipid synthesis, with SREBP-1a being responsible for regulating both FA and cholesterol synthesis, whereas SREBP-1C and SREBP-2 contribute to the regulation of FA synthesis and cholesterol synthesis, respectively [80]. As a regulator of lipid synthesis, SREBP-1 has been studied extensively in different species [81]. In bovine mammary gland, SREBP-1c is one of the mechanisms regulating milk fat synthesis [82]. Immortalised bovine mammary epithelial cell line can be used as an in vitro screening system to identify superior transgenes, and to improve genomic modification technological research, thereby improving the efficiency of transgenic animal production [83]. Transcriptional analysis of multiple genes sheds light on the number of genes involved in the immortalization of BME65Cs cells. A significant change (but not loss) of p16INK4a and p53 were found in BME65Cs cells, suggesting that the inhibition of senescent-relevant pathways contributes to theBME65Cs cell line immortalisation. Cycles of growth, differentiation, and apoptosis characterize the fate of mammary epithelial cells throughout the life of the individual. These cellular processes are under the control of steroid and peptide hormones [84]. Our understanding of the regulation of proliferative, differentiating, and apoptotic processes has made great progress in the past years. Extracellular hormones, growth factors or cytokines relay their effects on the transcription of genes through the recognition of specific receptors and intracellular signaling molecules. Prolactin and its receptor are particularly important for mammary development. Prolactin plays a role in the morphological and biochemical differentiation of the epithelial cells during pregnancy and regulates milk protein synthesis during lactation. The investigations into the molecular events underlying this crosstalk have yielded unexpected insights. It has been demonstrated that Stat5 (signal transducer and activator of transcription [85] and the glucocorticoid receptor (GR), the downstream effectors of prolactin and glucocorticoid hormones interact and exhibit transcriptional synergy [86] and transcriptional repression [87]. Prolactin binds to the extracellular domain of the prolactin receptor (PRL-R) and causes its dimerisation [88-90] which activates the Stat5 which binds to DNA sites in the nucleus known as GAS elements and modulates the activity of target genes, e.g. the $\beta$-casein gene [91-92].

\section{CONCLUSION}

MEC culture is a valuable tool for various crucial studies regarding transcriptional and proteomics relevance of cellular behavior, interaction, involution and pathology. Many challenges remain to be overcome if mammary epithelial cells are to advance significantly beyond the use as in vitro versatile models for mammary gland functioning. However, recent advances have no doubt presented researchers with novel alternatives that have furthered our understanding of how tissue structures arise in three dimensions. Perhaps ultimately such models could be tailored to provide environments typical of the virginal, gestational and involuting gland, so enhancing our understanding of disease processes in livestock.

\section{ACKNOWLEDGEMENT}

The authors would like to acknowledge the financial support of National Agricultural Innovation Project (NAIP).

\section{REFERENCES}

[1] Howlett, A.R., and Bissell, M.J. 1993. The influence of tissue microenvironment (stroma and extracellular matrix) on the development and function of mammary epithelium. Epithelial Cell Biol, 2:79e89.

[2] Haslam, S., and Woodward, T. 2003. Epithelial cell stromal interactions and ECM. Breast Cancer Res 5:208.

[3] Schor, S.L., and Schor, A.M. 2001. Phenotypic and genetic alterations in mammary stroma: implications for tumour progression. Breast Cancer Res, 3:373e9.

[4] Maffini, M.V., Soto, A.M., Calabro, J.M., Ucci, A.A., and Sonnenschein, C. 2004. The stroma as a crucial target in rat mammary gland carcinogenesis. J Cell Sci, 117:1495e502.

[5] Rose, M.T., and McConoche, H. 2006. The long road to a representative in vitro model of bovine lactation. JIfS, 3: $67-72$.

[6] Huynh, H.T., Robitaille, G., and Turner, J. 1991. Establishment of bovine mammary epithelial cells (MAC-t): an in vitro model for bovine lactation. Experimental Cell Research 197:191-199.

[7] Zavizion, B., Politis, I., and Gorewit, R.C. 1992. Bovine mammary myoepithelial cells. 1. Isolation, culture, and characterization. J Dairy Sci 75(12): 3367-3380.

[8] German T, Barash I .2002. Characterization of an epithelial cell line from bovine mammary gland. In Vitro Cell Dev Biol Anim 38(5): 282-292. 
[9] Pantschenko, A.G., Woodcock-Mitchell, J., Bushmich, S.L., and Yang, T.J. 2000. Establishment and characterization of a caprine mammary epithelial cell line (CMEC). In Vitro Cell Dev Biol Anim 36(1): 26-37.

[10] Zavizion, B., van Duffelen, M., Schaeffer, W., and Politis, I. 1996. Establishment and characterization of a bovine mammary epithelial cell line with unique properties. In Vitro Cell Dev Biol Anim 32(3): 138-148.

[11] Anand, V., Dogra, N., Singh, S., Kumar, S.N., Jena, M.K., Malakar, D., Dang, A.K., Mishra, B.P., Mukhopadhyay, T.K, Kaushik, J.K, and Mohanty, A.K. 2012. Establishment and Characterization of a Buffalo (Bubalus bubalis) Mammary Epithelial Cell Line. PLoS ONE 7(7).

[12] McGrath, M.F. 1987. A novel system for mammary epithelial cell culture. J Dairy Sci 70(9): 1967-1980.

[13] Ehmann, U.K., DeVries, J.T., Chen, M.S., Adamos, A.A., and Guzman, R.C. 2003. An in vitro model of epithelial cell growth stimulation in the rodent mammary gland. Cell Prolif 36(4): 177-190.

[14] Li, P., Wilde, C.J., Finch, L.M., Fernig, D.G., and Rudland, P.S. 1999. Identification of cell types in the developing goat mammary gland. Histochem J 31(6): 379-393.

[15] Matitashvili, E., and Bauman, D.E. 1999. Culture of primary bovine mammary epithelial cells. In Vitro Cell Dev Biol Anim 35(8): 431-434.

[16] Sommers, C.L., Walker-Jones, D., Heckford, S.E., Worland, P., Valverius, E., Clark, R., McCormick, F., Stampfer, M., Abularach, S., and Gelmann, E.P. 1989. Vimentin rather than keratin expression in some hormoneindependent breast cancer cell lines and in oncogene-transformed mammary epithelial cells. Cancer Res 49(15): 4258-4263.

[17] Rose, M.T., Aso, H., Yonekura, S., Komatsu, T., Hagino, A., Ozutsumi, K., Obara, Y. 2002. In vitro differentiation of a cloned bovine mammary epithelial cell. J Dairy Res 69(3): 345-355.

[18] Duchler, M., Schmoll, F., Pfneisl, F., Brem, G., and Schellander, K. 1998. OMEC II: Anew ovine mammary epithelial cell line. Biol Cell 90 (2): 199-205.

[19] Danielson, K.G., Obron, C.J., Durban, E.M., Butel, J.S., and Medina, D. 1984. Epithelial mouse mammary cell line exhibiting normal morphogenesis in vivo andfunctional differentiation in vitro. Proc Natl Acad Sci U S A 81: 3756-3760.

[20] Berdichevsky, F., Alfod, D., D'Souza, B., and Taylor-Papadimitriou, J. 1994. Branching morphogenesis of human mammary epithelial cells in collagen gels. J Cell Sci 107: 3557-3568.

[21] Berdichevsky, F., Gilbert, C., Shearer, M., and Taylor-Papadimitriou, J. 1992. Collagen- induced rapid morphogenesis of human mammary epithelial cells: The role of a2 b1 integrins. J Cell Sci 102: 437-446.

[22] Bartek, J., Durban, E.M, Hallowes, R.C., Taylor-Papadimitriou, J. 1985. A subclass of luminal epithelial cells in the mammary gland, defined by antibodies to cytokeratins. J Cell Sci 75: 17-33.

[23] Cifrain, E., Guidry, A.J., O’Brien, C.N., Nickerson, S.C., and Marquardt, W.W. 1994. Adherence of Staphylococcus aureus to cultured bovine mammary epithelial cells. J Dairy Sci 77: 970-983.

[24] Aoki, N. 2006. Regulation and functional relevance of milk fat globules and their components in the mammary gland. Biosci Biotechnol Biochem 70: 2019-2027.

[25] Mather, I.H., and Jack, L.J. 1993. A review of the molecular and cellular biology of butyrophilin, the major protein of bovine milk globule membrane. J Dairy Sci 76: 3832-3850.

[26] Franke, W.W., Heid, H.W., Grund, C.,Winter, S., Freudenstein, C., Schmid, E., Jarasch, E.D., and Keenan, T.W. 1981. Antibodies to the major insoluble milk fat globule membrane-associated protein: specific location in apical regions of lactating epithelial cells. J Cell Biol 89: 485-494.

[27] Hu, H., Wang, J., Bu, D., Wei, H., and Zhou, L. 2009. In vitro culture and characterization of a mammary epithelial cell line from Chinese Holstein dairy cow. PLoS ONE 4: e7636.

[28] St-Pierre, N.R., Cobanov, B., Schnitkey, G. 2003. Economic losses from heat stress by U.S. livestock industries. J Dairy Sci 86:E52-77.

[29] Du, J., Di, H.S., and Wang, G.L. 2007. Establishment of a bovine epithelial mammary cell line and its ultrastructural changes when exposed to heat stress. Sheng Wu Gong Cheng Xue Bao 23: 471-476.

[30] Ritossa, F. 1962. A new puffing pattern induced by heat shock and DNP in Drosophila. Experientia 18:571-573.

[31] Lauzon, K., Zhao, X., Bouetard, A., Delbecchl, L., Paquette, B., and Lacasse, P. 2005. Antioxidants to prevent bovine neutrophil-induced mammary epithelial cell damage. J Dairy Sci 88:4295-4303.

[32] Collier, R.J., Stiening, C.M., Pollard, B.C., VanBaale, M.J., Baumgard, L.H., Gentry, P.C., and Coussens, P.M. 2006. Use of gene expression microarrays for evaluating environmental stress tolerance at the cellular level in cattle. J. Anim. Sci. 84:E1-E13. 
[33] Zhao, K., Liu, H.Y., Zhou, M.M., and Liu, J.X. 2010. Establishment and characterization of a lactating bovine mammary epithelial cell model for the study of milk synthesis. Cell Biol Inter 34: 717-721.

[34] Kapila, N., Kishore, A., Sodhi, M., Sharma, A., Kumar, P., Mohanty, A.K., Jerath, T., and Mukesh, M. 2012. Identification of appropriate reference genes for qRT-PCR analysis of heat stressed mammary epithelial cells in riverine buffaloes (Bubalus bubalis). ISRN Biotech.

[35] Collier, R.J., Collier, J.L., Rhoads, P., and Baumgard, L.H. 2008. Invited Review: Genes involved in the bovine heat stress response. J Dairy Sci 91:445-454.

[36] Buse, P., Woo, P.L., Alexander, D.B., Reza, A., and Firestone, G.L. 1995. Glucocorticoid-induced functional polarity of growth factor responsiveness regulates tight junction dynamics in transformed mammary epithelial tumor cells. J. Biol. Chem. 270: 28223-28227.

[37] Wong, V., Ching, D., McCrea, P.D., and Firestone, G.L.1999. Glucocorticoid down-regulation of fascin protein expression is required for the steroid- induced formation of tight junctions and cell-cell interactions in rat mammary epithelial tumor cells. J. Biol. Chem. 274:5443-5453.

[38] O’Brien, L.E., Zegers, M.M. and Mostov, K.E. 2002. Opinion: building epithelial architecture: insights from threedimensional culture models. Nat. Rev. Mol. Cell Biol. 3:531-537.

[39] Debnath, J., Muthuswamy, S.K., and Brugge, J.S. 2003. Morphogenesis and oncogenesis of MCF-10A mammary epithelial acini grown in three-dimensional basement membrane cultures. Methods. 30: 256e68.

[40] Woo, P.L., Ching, D., Guan, Y., and Firestone, G.L. 1999. Requirement for Ras and phosphatidylinositol 3-kinase signaling uncouples the glucocorticoid-induced junctional organization and transepithelial electrical resistance in mammary tumor cells. J. Biol. Chem. 274:32818-32828.

[41] Rubenstein, N.M., Guan, Y., Woo, P.L., and Firestone, G.L. 2003. Glucocorticoid down-regulation of RhoA is required for the steroid-induced organization of the junctional complex and tight junction formation in rat mammary epithelial tumor cells. J. Biol. Chem. 278:10353-10360.

[42] Watson, C.J., and Burdon, T.G. 1996. Prolactin signal transduction mechanisms in the mammary gland: the role of the Jak/Stat pathway. Rev Reprod, 1:1-5.

[43] Streuli, C.H., Edwards, G.M., Delcommenne, M., Whitelaw, B.C., Burdon, T.G., Schindler, C., Watson, C.J. 1995 Stat5 as a Target for regulation by extracellular matrix. J Biol Chem; 270: 21639-44.

[44] Xu, R., Nelson, C.M., Muschler, J.L., Veiseh, M., Vonderhaar, B.K., and Bissell, M.J. 2009. Sustained activation of STAT5 is essential for chromatin remodeling and maintenance of mammary-specific function. $\mathrm{J}$ Cell Biol, 184:57-66.

[45] El-Sabban, M.E., Sfeir, A.J., Daher, M.H., Kalaany, N.Y., Bassam, R.A., Talhouk, R.S. 2003. ECM-induced gap junctional communication enhances mammary epithelial cell differentiation. J Cell Sci, 116:3531-41.

[46] O’Brien, L.E., Jou, T.S., Pollack, A.L., Zhang, Q., Hansen, S.H., Yurchenco, P., and Mostov, K.E. 2001. Rac1 orientates epithelial apical polarity through effects on basolateral laminin assembly. Nat Cell Biol, 3:831-8.

[47] Haslam, S.Z., and Woodward, T.L. 2003. Host microenvironment in breast cancer development: epithelial-cellstromal-cell interactions and steroid hormone action in normal and cancerous mammary gland. Breast Cancer Res, 5:208e15.

[48] Sakakura, T., Nishizuka, Y., and Dawe, C.D. 1976. Mesenchyme-dependent morphogenesis and epitheliumspecific cytodifferentiation in mouse mammary gland. Science, 194:891-3.

[49] Naylor, M.J., Ormandy, C.J. 2002. Mouse strain-specific patterns of mammary epithelial ductal side branching are elicited by stromal factors. Dev Dyn, 225:100-5.

[50] Blum, J.L., and Wicha, M.S. 1988. Role of the cytoskeleton in laminin induced mammary gene expression. J. Cell. Physiol. 135: 13-22.

[51] Krause, S., Maffini, M.V., Soto, A.M., and Sonnenschein, C. 2008. A novel 3D in vitro culture model to study stromal-epithelial interactions in the mammary gland. Tissue Eng Part C Methods, 14: 261e71.

[52] Pickl, M., and Ries, C.H. 2009. Comparison of 3D and 2D tumor models reveals enhanced HER2 activation in 3D associated with an increased response to trastuzumab. Oncogene, 28:461e8.

[53] Shaw, K.R., Wrobel, C.N., and Brugge, J.S. 2004. Use of three-dimensional basement membrane culture to model oncogene-induced changes in mammary epithelial morphogenesis. J Mammary Gland Biol Neoplasia, 9:297e310.

[54] Ip, M.M., and Darcy, K.M. 1996. Three-dimensional mammary primary culture model systems. J Mammary Gland Biol Neoplasia, 1:91e110. 
[55] Kabotyanski, E.B., Rijnkels, M., Freeman-zadrowski, C., Buser, A.C., Edwards, D.P., and Rosen, J.M. 2009. Lactogenic hormonal induction of long distance interactions between beta-casein gene regulatory elements. J. Biol. Chem., 284: 22815-24.

[56] Gudjonsson, T., Ronnov-Jessen, L., Villadsen, R., Rank, F., Bissell, M.J., and Petersen, O.W. 2002. Normal and tumor-derived myoepi mycthelial cells differ in their ability to interact with luminal breast epithelial cells for polarity and basement membrane deposition. J Cell Sci, 115: 39-50.

[57] Petersen, O.W., Ronnov-Jessen, L., Howlett, A.R., and Bissell, M.J. 1992. Interaction with basement membrane serves to rapidly distinguish growth and differentiation pattern of normal and malignant human breast epithelial cells. Proc Natl Acad Sci USA, 89: 9064-9068.

[58] Streuli, C.H., and Bissell, M.J. 1990. Expression of extracellular matrix components is regulated by substratum. J Cell Biol, 110: 1405-1415.

[59] Weaver, V.M., Lelievre, S., Lakins, J.N., Chrenek, M.A., Jones, J.C., Giancotti, F., Werb, Z., Bissell, M.J. 2002. B4 integrin-dependent formation of polarized three-dimensional architecture confers resistance to apoptosis in normal and malignant mammary epithelium. Cancer Cell, 2: 205-216.

[60] Delabarre, S., Claudon, C., Laurent, F. 1997. Influence of several extracellular matrix components in primary cultures of bovine mammary epithelial cells. Tissue Cell, 29: 99-106.

[61] Kozlowski, M., Gajewska, M., Majewska, A., Jank, M., and Motyl, T. 2009. Differences In Growth And Transcriptomic Profile Of Bovine Mammary Epithelial Monolayer And Three-Dimensional Cell Cultures. Journal of Physiology and Pharmacology, Suppl 1: 5-14.

[62] Debnath, J., Mills, K.R., Collins, N.L., Reginato, M.J., Muthuswamy, S.K., and Brugge, J.S. 2002. The role of apoptosis in creating and maintaining luminal space within normal and oncogene expressing mammary acini. Cell, 111: 29-40.

[63] Xian, W., Schwertfeger, K.L., Vargo-Gogola, T., and Rosen, J.M. 2005. Pleiotropic effects of FGFR1 on cell proliferation, survival, and migration in a 3D mammary epithelial cell model. J Cell Biol, 171: 663-673.

[64] Zhao, F.Q., Okine, E.K., and Kennelly, J.J. 1999. Glucose transporter gene expression in bovine mammary gland. J Anim Sci 77: 2517-2522.

[65] Thorens, B., and Mueckler, M. 2010. Glucose transporters in the 21st Century. Am J Physiol Endocrinol Metab 298: E141-145.

[66] Zhao, F.Q., and Keating, A.F. 2007. Expression and regulation of glucose transporters in the bovine mammary gland. J Dairy Sci 90 Suppl 1: E76-86.

[67] Burant, C.F., Sivitz, W.I., Fukumoto, H., Kayano, T., Nagamatsu, S., Seino ,S., Pessin, J.E., and Bell, G.I. 1991. Mammalian glucose transporters: structure and molecular regulation. Recent Prog Horm Res 47: 349-387: 387348.

[68] Uldry, M., and Thorens, B. 2004. The SLC 2 family of facilitated hexose and polyol transporters. Pflugers Arch 447: 480-489.

[69] Cant, J.P., Trout, D.R., Qiao, F., and Purdie, N.G. 2002. Milk synthetic response of the bovine mammary gland to an increase in the local concentration of arterial glucose. J Dairy Sci. 85: 494-503.

[70] Zhao, K., Liu, H. Y., Wang, H. F., Zhou, M. M., and Liu, J. X. 2012. Effect of glucose availability on glucose transport in bovine mammary epithelial cells. Animal, 6: 488-493.

[71] Plas, D.R., Rathmell, J.C. and Thompson, C.B. 2002. Homeostatic control of lymphocyte survival: potential origins and implications. Nature Immunology 3: 515-521.

[72] Nutt, L.K., Margolis, S.S., Jensen, M., Herman, C.E., Dunphy, W.G., Rathmell, J.C. and Kornbluth, S. 2005. Metabolic regulation of oocyte cell death through the CaMKII-mediated phosphorylation of caspase-2. Cell 123: 89-103.

[73] Buchakjian, M.R., and Kornbluth, S. 2010. The engine driving the ship: metabolic steering of cell proliferation and death. Nature Reviews Molecular Cell Biology 11: 715-727.

[74] Mulukutla, B.C., Khan, S., Lange, A., and Hu, W.S. 2010. Glucose metabolism in mammalian cell culture: new insights for tweaking vintage pathways. Trends in Biotechnology 28: 476-484.

[75] Aboagye, E.O., and Bhujwalla, ZM. 1999. Phospholipid Metabolism of Human Mammary Epithelial Cells Malignant Transformation Alters Membrane Choline. Cancer Res 59: 80-84.

[76] Miettinen, J., Ebner, R., Lopez, A. R., and Derynck, R. 1994. TGF $\beta$ Induced Transdifferentiation of Mammary Epithelial Cells to Mesenchymal Cells: Involvement of Type I Receptors. J Cell Biol. 127:2021-36.

[77] Boudreau, N., Sympson, C.J., Werb, Z., and Bissell MJ. 1995. Suppression of ICE and Apoptosis in Mammary Epithelial Cells by Extracellular Matrix. Science, 267(5199): 891-893. 
[78] Casey, T., Dover, H., Liesman, J., DeVries, L., Kiupel, M., VandeHaar, M., and Plaut, K. 2011. Transcriptome Analysis of Epithelial and Stromal Contributions to Mammogenesis in Three Week Prepartum Cows. PLoS ONE, 6(7): e22541.

[79] Shimano, H. 2001. Sterol regulatory element-binding proteins (SREB-Ps): Transcriptional regulators of lipid synthetic genes. Prog. Lipid Res. 40:439-452.

[80] Horton, J. D. 2002. SREBPs: Activators of the complete program of cholesterol and fatty acid synthesis in the liver. J. Clin. Invest. 109:1125-1131.

[81] Brown, M. S., and Goldstein, J. L. 1997. The SREBP pathway: Regulation of cholesterol metabolism by proteolysis of a membrane-bound transcription factor. Cell 89:331-340.

[82] Bauman, D. E., Perfield, J.W., Harvatine, K. J., and Baumgard, L. H. 2008. Regulation of fat synthesis by conjugated linoleic acid: Lactation and the ruminant model. J. Nutr. 138: 403-409.

[83] Lubo, H., and Palmer, C. 2000. Transgenic animal bioreactors-where we are. Transgenic Res, 9:301-304.

[84] Topper, Y.J., and Freeman, C.S. 1980. Multiple hormone interactions in the developmental biology of the mammary gland. Physiol Rev. 60:1049-106.

[85] Rosen, J.M., Wyszomierski, S.L., and Hadsell, D. 1999. Regulation of milk protein gene expression. Ann Rev Nutr, 19:407-36.

[86] Cella, N., Groner, B., and Hynes, N.E. 1998. Characterisation of Stat5a and Stat5b homodimers and heterodimers and their association with the glucocorticoid receptor in mammary cells. Mol Cell Biol.18:1783-92.

[87] Stoecklin, E.,Wissler, M., Gouilleux, F., Groner, B. 1996. Functional interactions between Stat5 and the glucocorticoid receptor. Nature (London), 383:726-8.

[88] Doppler, W. 1994. Regulation of gene expression by prolactin. Rev Physiol Biochem Pharmacol, 124: 93-130.

[89] Groner, B., and Gouilleux, F. 1995. Prolactin mediated gene activation in mammary epithelial cells. Curr Opin Genet Dev, 5:587-94.

[90] Hynes, N.E., Cella, N., and Wartmann, M. 1997. Prolactin stimulated pathways in mammary epithelial cells. J Mammary Gland Biol Neoplasia, 1:207-14.

[91] John, S., Vinkemeier, U., Soldaini, E., Darnell, J.E., and Leonard, W.J. 1999. The significance of tetramerization in promoter recruitment by Stat5. Mol Cell Biol, 19:1910-8.

[92] Kazansky, A.V., Raught, B., Lindsey, S.M., Wang, Y.F., and Rosen, J.M. 1995. Regulation of mammary gland factor/Stat5a during mammary gland development. Mol Endocrinol, 9:1598-609. 